\title{
The Impact of Mineral Salts and Milk of Lime on Physicochemical Parameters and Swelling :( Case of Clays of Tlemcen Algeria)
}

\author{
Zeyne b Belabbaci ${ }^{1, *}$, Sidi Mohamed Aiss a Mamoune ${ }^{2}$, Abde Imalek Bekkouche ${ }^{2}$ \\ ${ }^{1}$ RISAM Laboratory, Faculty of Technology, University Aboubekr Belkaïd Tlemcen, BP 230, Algeria \\ ${ }^{2}$ University CenterT'émouchent, Bp 284 46000, Algéria
}

\begin{abstract}
Clay soil is the foundation for many buildings. So me families have the characteristic to be swelling or shrink. However, construction on this type of soil requires a good companion for the recognition of identification and characterization of their swelling potential. In this work we are interested by two aspects: -The first is on the tests recommended for the identification of four expansive soils in the region of Tlemcen (Algeria); -The second is to assess the influence of the addition of milk of lime and mineral salts ( $\mathrm{KCl}$ Potassium Chloride, Magnesium Ch loride $\mathrm{MgCl}_{2}$ ) at different percentages on the physico-chemical parameters, the swelling potential of these soils from correlations approximate estimates. The results obtained show that stabilization by the addition of milk of lime modifies the physico-chemical characteristics of soil and the results are quite satisfactory in significantly reducing the phenomena of swelling, as regards stabiliztion with milk of lime we notethat the salt concentration has little influence on the potential of swelling and it differs from one another salt.
\end{abstract}

Keywords Clay, Milk of lime, Swelling, Stabilization,Sa lts, $\mathrm{KCl}, \mathrm{MgCl}_{2}$

\section{Introduction}

Excessive heave, settlement, low shear strength, and internal erosion of soils can cause damage to engineering structures. In order to overcome these difficulties and to prevent structural damages during the site selection and/or construction stages, engineers have developed several techniques. They avoid potential soil problems by selecting an alternative site or by removing the undesirable soil and replacing it with desirable soil.

Engineering designs have been adopted for the conditions at hand, lastly the soil can be improved. The last approach, improvement or stabilization of a soil, is becoming the more attractive method for the soil engineers.

Stabilization of clay soils using lime, cement, salts has long been used to improve the workability and mechanical characteristics of the soils in geotechnical engineering[5].

Some attempts have shown that the addition of a material such as salts or the milk of lime appearance modifies the physico-chemical parameters, and reduced the swelling in a

* Corresponding author:

bellabacizyn@yahoo.fr (Zeyneb Belabbaci)

Published online at http://journal.sapub.org/jce

Copyright (C) 2012 Scientific \& Academic Publishing. All Rights Reserved remarkable manner.

This result has to consider the addition of this type of material is a technique of stabilization promising. This concept is the subject of this study.

\section{Localization of the Site and Geotechnical Identification}

The soils objects of this study are reworked clays coming from different regions of Tlemcen (north west of Algeria), in an active area of swelling perspective (figure 1).

Whatever the objectives sought in geotechnical study, the rule is to make initial identification of concerned soils. This procedure is used to guide further geotechnical analys is and especially to make a classification of encountered materials. The parameters required for this classification are both physico-chemical and granulo metric.

The results of all tests performed on the four soils studied are listed in Table 1:

The identification tests and physico-chemical classification of the GTR (Technical Design Guide Earthworks and Subgrade; LCPC, SETRA 1992), show that soil 1 and 2 are very plastic clays marls, Class A 3. About soils 3, 4 they are pure clay, very plastic with very little calciu $\mathrm{m}$ carbonate, and belong to the classA 4 . 


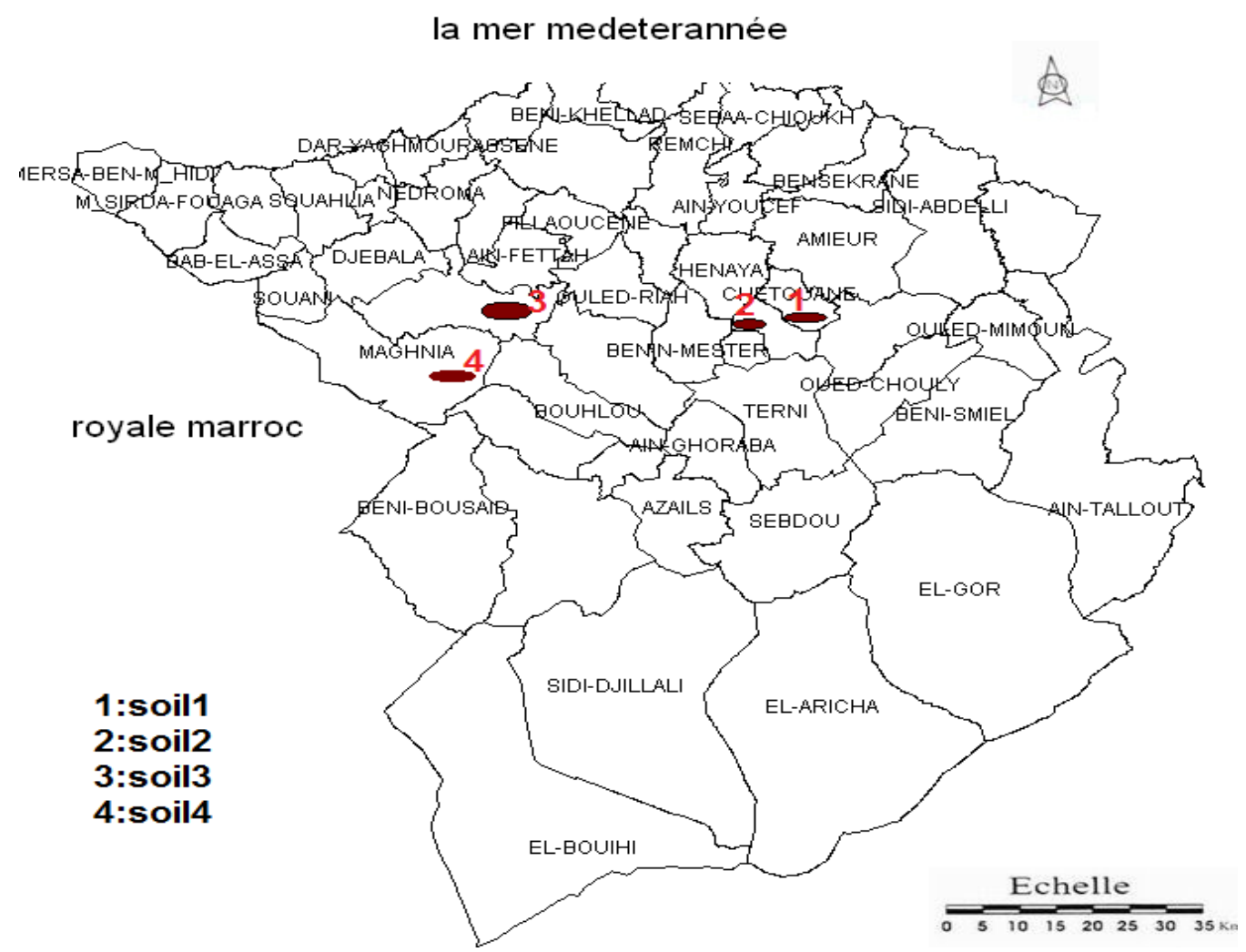

Figure 1. The geographical situation of studied sites geographical situation of studied sites

Table 1. Physicochemical characteristics of T lemcen clays

\begin{tabular}{|c|c|c|c|c|}
\hline Symbol & Soil1 & Soil2 & Soil3 & Soil4 \\
\hline Profondeur (m) & 3 & 4 & 8 & 6 \\
\hline$\gamma_{\mathrm{d}}\left(\mathrm{kN} / \mathrm{m}^{3}\right)$ & 15,82 & 16,19 & 16,5 & 13,33 \\
\hline $\mathrm{W}_{\mathrm{opm}}(\%)$ & 24,6 & 23 & 21,4 & 33 \\
\hline$<80 \mu(\%)$ & 90 & 94 & 90 & 85 \\
\hline$(\%)$ organic matter & 1.22 & 1.67 & 1.91 & 1.77 \\
\hline$<2 \mu(\%)$ & 44 & 48 & 44.8 & 50 \\
\hline $\mathrm{w}_{\mathrm{l}}(\%)$ & 67 & 66,3 & 68,45 & 136 \\
\hline $\mathrm{w}_{\mathrm{p}}(\%)$ & 29,58 & 30 & 26,41 & 48,06 \\
\hline $\mathrm{I}_{\mathrm{p}}(\%)$ & 37,42 & 36,2 & 42,04 & 87,94 \\
\hline $\mathrm{W}_{\mathrm{R}}(\%)$ & 4,2 & 2,3 & 7.01 & 11 \\
\hline$I_{R} \quad(\%)$ & 62,8 & 64 & 59,55 & 125 \\
\hline $\mathrm{A}_{\mathrm{C}}$ & 0,850 & 0,754 & 0,938 & 1,107 \\
\hline Vbs & 8.4 & 6.15 & 9.6 & 43.22 \\
\hline S. S.T $\left(\mathrm{m}^{2} / \mathrm{g}\right)$ & 176.4 & 129.15 & 201,6 & 907.62 \\
\hline $\mathrm{TCaCo} 3(\%)$ & 13,84 & 16,45 & 2,469 & 1.89 \\
\hline Class GTR & A3 & A3 & A4 & A4 \\
\hline
\end{tabular}

\section{The Mineralogy Structure of Clay Expansive}

It is necessary to present the crystallographic structures of different families of clay (common) to better understand relations between water and clay.
Clays and micas are part of the family of phyllo silicates. The crystal lattice of phyllo silicates is based on an array of $\mathrm{SiO} 4$ tetrahedra (Figure 2). Each tetrahedron $\mathrm{SiO} 4$ tetrahedra sharing 3sommets with neighbors; vertex set is a shared assembly hexagonal plane. The apex tetrahedron that is not in the plan is shared an octahedron AlO6 (Figure 2). It is the combination of tetrahedral layers $(\mathrm{T})$ and octahedral layers (O) which is the justification of the crystal lattice each of clay.

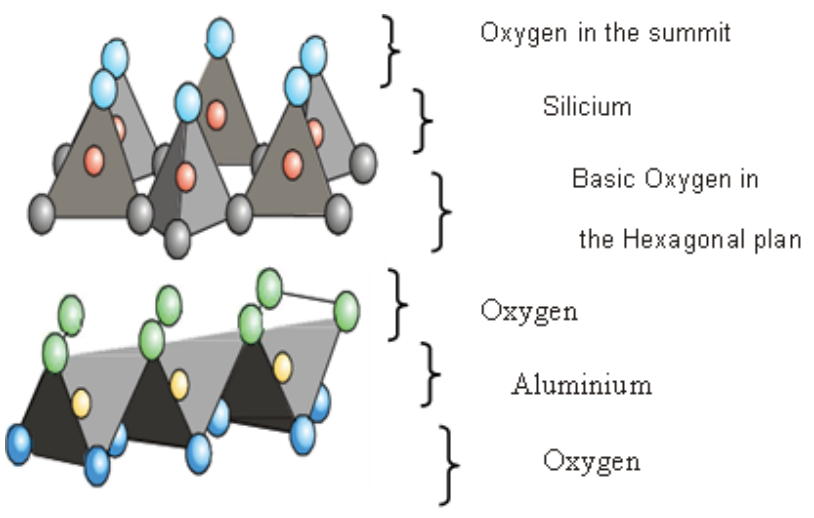

Figure 2. tetrahedron Structure ( $\mathrm{SiO} 4)$ and octahedron Structure( $\mathrm{A} 12 \mathrm{O} 6)$

\section{Classification of Expansive Soils}

Carry out a proper classification of expansive soils implies that the geotechnical parameters are known representative of the swelling. The problem lies in the definition of these parameters[13]. Practice has it that the pressure and the 
magnitude of swelling that are used to characterize expansive soils.

Table 2. Empirical approaches Bet ween hysicochemical characteristics and swelling

\begin{tabular}{|c|c|c|c|c|}
\hline \multicolumn{2}{|c|}{ Altmeyer (1955) } & \multicolumn{3}{c|}{ Seed, Woodward et Lungreen(1962) } \\
\hline $\mathrm{W}_{\mathrm{R}}(\%)$ & $\begin{array}{c}\text { Swelling } \\
\text { Potential }\end{array}$ & $\begin{array}{c}\text { Taux de } \\
\text { gonflement }\end{array}$ & Sp (\%) & $\mathrm{Ip}$ \\
\hline$<10$ & High & Low & $0-1,5$ & $0-10$ \\
\hline $10-12$ & Critical & Medium & $1,5-5$ & $10-20$ \\
\hline$>12$ & Low & High & $5-25$ & $20-35$ \\
\hline \multicolumn{2}{|c|}{ Snethen $(1980)$} & Ranganatham et Satyanarayan (1965) \\
\hline $\begin{array}{c}\text { Swelling } \\
\text { Potential }\end{array}$ & Ip & $\begin{array}{c}\text { Swelling } \\
\text { Potential }\end{array}$ & \multicolumn{2}{|c|}{$\mathrm{I}_{\mathrm{R}}$} \\
\hline Very High & $>35$ & Low & \multicolumn{2}{|c|}{$0-20$} \\
\hline High & $22-48$ & Medium & \multicolumn{2}{|c|}{$20-30$} \\
\hline Medium & $22-32$ & High & \multicolumn{2}{c|}{$30-60$} \\
\hline Low & $<18$ & Very High & \multicolumn{2}{|c}{$>60$} \\
\hline
\end{tabular}

The literature contains a considerable number of empirical approaches that assess the swelling potential of soils. So me authors believe this potential link to a single parameter. Thus, as shown in Table 2, below, Altmeyer, Ranganatham and
Satyanarayan[3], and Snethen[3]propose classifications which give respectively the swelling potential depending WR, IR,IP (Table 3).

\section{Correlation Between Swelling and Physico-Chemical Parameters}

To test the comparis on of the classifications listed above, they have been applied to soil samples from sites of Tle mcen, The identifications are given in Table 4.

Of these classifications, there emerges the following remarks:

Some classifications like that of Altmeyer tend to overestimate the swelling potential of soils as it provides all the samples as highly expansive.

The various classifications do not converge to the same qualification all the expansive potential for the same sample.

These contradictions find their explanation in the number and nature of the parameters taken into account by each of these classifications. It should be noted that the determining parameters in the expansive character of a soil are known. By cons, the influence of each parameter in this expansive is difficult to quantify.

Table 3. empirical approaches Between hysicochemical characteristics and swelling

\begin{tabular}{|c|c|c|c|c|c|c|c|c|}
\hline \multicolumn{5}{|c|}{ Holtz Et Gibbs (1956) } & \multicolumn{4}{|c|}{ Ghen (1988) } \\
\hline$\stackrel{\vec{N}}{\tilde{E}}$ & $\frac{\sqrt{6}}{e^{\circ}}$ & $\overbrace{\%}^{\sum}$ & $\overbrace{e^{\circ}}^{\sqrt{0}}$ & 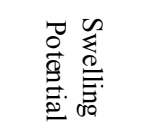 & $\underset{\stackrel{D}{E}}{\stackrel{E}{E}}$ & $\underset{e}{\stackrel{a}{a}}$ & 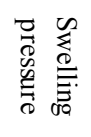 & 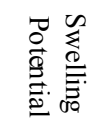 \\
\hline$>28$ & $>35$ & $<10$ & $>30$ & Very High & $>95$ & $>60$ & 10 & $\begin{array}{l}\text { Very } \\
\text { High }\end{array}$ \\
\hline $20-30$ & $20-40$ & $7-10$ & $20-30$ & High & $60-95$ & $40-60$ & $2.5-5$ & High \\
\hline $13-23$ & $15-30$ & $10-15$ & $10-30$ & Medium & $30-60$ & $30-40$ & $1.5-2.5$ & Medium \\
\hline$<15$ & $<18$ & $>15$ & $<10$ & Low & $<30$ & $<30$ & $<0.5$ & Low \\
\hline \multicolumn{9}{|c|}{ Holtz, Dakshanamurphy et Raman(1973) } \\
\hline \multicolumn{3}{|c|}{ Swelling Potential } & \multicolumn{2}{|c|}{$\operatorname{Ip}(\%)$} & \multicolumn{2}{|l|}{$\mathrm{W}_{\mathrm{R}}(\%)$} & \multicolumn{2}{|c|}{$\mathrm{W}_{\mathrm{L}}(\%)$} \\
\hline \multicolumn{3}{|c|}{ Low } & \multicolumn{2}{|c|}{$<18$} & \multicolumn{2}{|l|}{$>15$} & \multicolumn{2}{|c|}{$35-20$} \\
\hline \multicolumn{3}{|c|}{ Medium } & \multicolumn{2}{|c|}{$25-15$} & \multicolumn{2}{|l|}{$15-10$} & \multicolumn{2}{|c|}{$50-35$} \\
\hline \multicolumn{3}{|c|}{ High } & \multicolumn{2}{|c|}{$41-25$} & \multicolumn{2}{|l|}{$12-7$} & \multicolumn{2}{|c|}{$70-50$} \\
\hline \multicolumn{3}{|c|}{ Very High } & \multicolumn{2}{|c|}{$>35$} & $<11$ & & \multicolumn{2}{|c|}{$>70$} \\
\hline
\end{tabular}

Table 4. Classification of studied soils

\begin{tabular}{|c|c|c|c|c|c|c|c|}
\hline soils & Altmeyer & $\begin{array}{c}\text { Ranganatand } \\
\text { al }\end{array}$ & Snethen & $\begin{array}{c}\text { Seed, } \\
\text { Woodward et } \\
\text { Lungreen }\end{array}$ & Ghen & Holtz Gibbs & $\begin{array}{c}\text { Holtz, } \\
\text { Dakshanamurthy }\end{array}$ \\
\hline Soil1 & F & VF & VH & H & VH & VH & F \\
\hline Soil2 & F & VF & VH & H & H & H & F \\
\hline Soil3 & F & F & VH & H & VH & VH & F \\
\hline Soil4 & L & VF & VH & H & VH & VH & T F \\
\hline
\end{tabular}

F: fort ; C:critical TF: Very fort; H: High; VH: Very High; L:low 


\section{Physics-Chemical Variation of The parameters According to Percentages of Milk of Lime}
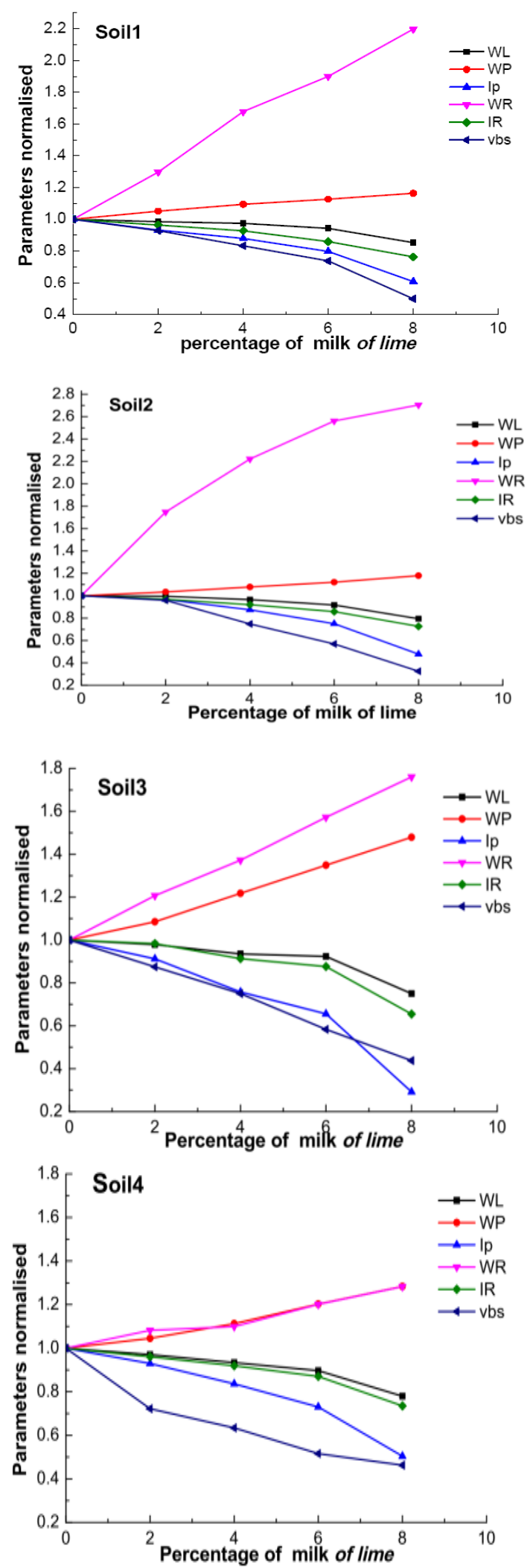

Figure 4. Physics-chemical variation of the parameters according to percentages of milk of lime
The swelling of soils is sometimes correlated with some physico-chemical parameters in order to study the influence of stabilization on these parameters, measurements of Atterberg limits and VBS were made with milk of lime at different percentages.

Figure 4 shows the path followed by the clays of Tlemcen after treatment with $2 \%-4 \%-6 \%-8 \%$ milk of lime.

We notice that the clays which high plasticity seen after treatment with milk of lime, consistence progress to low plasticity. This change in the consistence related to the percentage of milk of lime, translates into a decrease of plasticity index which partly due to ionic reactions of milk of lime (excess of cations calcium) with clay minerals which causes a flocculation of the soil, and partly by an exchange of calcium with other cations in the structure of the clay. We also note a continued decrease in blue value and the index of shrinkage according to the increased percentage of milk of lime.

\section{Correlation between Physicochemical Parameters and Swelling after Using $8 \%$ af Milk af Lime}

A correlation between physicochemical parameters and swelling occurred after the use of $8 \%$ of milk of lime, we see that the swelling is reduced after the use of milk of lime, For example for the soil 1 according to the classification of Holtz is a past from a high potential to medium potential (table 5).

Table 5. Correlation between physicochemical parameters and swelling after using $8 \%$ of milk of lime

\begin{tabular}{|c|c|c|c|c|c|c|c|}
\hline soils & 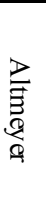 & 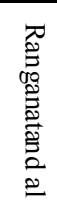 & 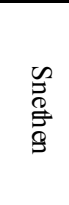 & 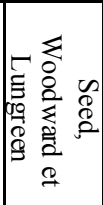 & $\stackrel{\Omega}{\Omega}$ & 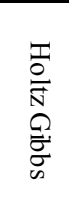 & 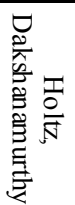 \\
\hline Soill & $\mathrm{F}$ & $\mathrm{F}$ & $\mathrm{M}$ & $\mathrm{H}$ & $\mathrm{M}$ & $\mathrm{M}$ & $\mathrm{M}$ \\
\hline Soil2 & $\mathrm{F}$ & $\mathrm{F}$ & $\mathrm{H}$ & $\mathrm{H}$ & $\mathrm{H}$ & $E$ & $\mathrm{M}$ \\
\hline Soil3 & $\mathrm{C}$ & $\bar{F}$ & $\mathrm{M}$ & $\overline{\mathrm{H}}$ & $\mathrm{H}$ & $\mathrm{M}$ & $\mathrm{M}$ \\
\hline Soil4 & $\mathrm{L}$ & $\mathrm{VF}$ & $\mathrm{VH}$ & $\mathrm{H}$ & $\mathrm{VH}$ & $\mathrm{VH}$ & $\mathrm{VH}$ \\
\hline
\end{tabular}

F: fort ; C:critical; VF: Very fort; H: High; VH: Very High; L:low

\section{Action of Mineral Salts on the Physicochemical Parameters of Studied Soils}

We have conducted a study on the effect of salts on the physical-chemical parameters this study is addressed to four soils.

Tables 6, 7 represent the variation of physicochemical parameters depending of salt Concentrations $(0.05,0.1,0.2$ $\mathrm{mol} / \mathrm{l})$ for different types of salts $\left(\mathrm{KCl}, \mathrm{MgCl}_{2}\right)$.

The results show that the influence of salts on the physicochemical parameters depends on the nature the salts used and their concentrations.

Compared to $\mathrm{kcl}$, magnesium chloride has the effect of decreasing over the liquid limit and plasticity index and the blue value. 
Table 6. Identification characteristics studied materials in the presence of saline solutions (Soill,2)

\begin{tabular}{|c|c|c|c|c|c|c|c|c|}
\hline \multirow{2}{*}{$\begin{array}{l}\frac{\tilde{O}}{0} \\
\frac{\theta}{\omega}\end{array}$} & \multirow{2}{*}{ 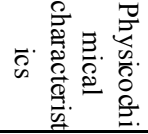 } & \multicolumn{4}{|c|}{$\mathrm{KCL}(\mathrm{mol} / \mathrm{l})$} & \multicolumn{3}{|c|}{$\operatorname{MgCL}_{2}(\mathrm{~mol} / \mathrm{l})$} \\
\hline & & 0 & 0.05 & 0.1 & 0.2 & 0.05 & 0.1 & 0.2 \\
\hline \multirow{6}{*}{ Soil 1} & $\mathrm{~W}_{1}$ & 67 & 66 & 66,3 & 65.5 & 67.2 & 65.25 & 63.45 \\
\hline & $\mathrm{Wp}$ & 29,58 & 30,1 & 30,28 & 31.2 & 31.15 & 33.21 & 32.5 \\
\hline & IP & 37,42 & 35.9 & 36.02 & 34.3 & 35.7 & 33.03 & 30.95 \\
\hline & $\mathrm{W}_{\mathrm{R}}$ & 4.2 & 4,40 & 4,8 & 5.2 & 5.3 & 6.2 & 7.5 \\
\hline & IR & 62.8 & 61.6 & 61.5 & 60.3 & 61.9 & 59.02 & 55.95 \\
\hline & VBS & 8.4 & 8 & 8.2 & 8.04 & 8 & 7.5 & 7.8 \\
\hline \multirow{6}{*}{ Soil 2} & $\mathrm{~W}_{1}$ & 66.3 & 65.5 & 65 & 64.3 & 65.8 & 64.85 & 64.21 \\
\hline & $\mathrm{W}_{\mathrm{p}}$ & 30 & 30,02 & 31,35 & 31.5 & 32.25 & 33.42 & 33.86 \\
\hline & $\mathrm{I}_{\mathrm{P}}$ & 36,2 & 35.48 & 33.65 & 32.8 & 33.55 & 31.43 & 30.38 \\
\hline & $\mathrm{W}_{\mathrm{R}}$ & 2,3 & 3,05 & 4,22 & 4.5 & 4.05 & 5.2 & 5.8 \\
\hline & $I_{R}$ & 64 & 62.45 & 60.78 & 59.8 & 61.75 & 59.65 & 58.41 \\
\hline & VBS & 6.15 & 6,2 & 6,1 & 6 & 5.7 & 5.4 & 4.2 \\
\hline
\end{tabular}

Table 7. Identification characteristics studied materials in the presence of saline solutions $(\mathrm{SoiB}, 4)$

\begin{tabular}{|c|c|c|c|c|c|c|c|c|}
\hline \multirow{2}{*}{$\begin{array}{l}\tilde{D} \\
\text { O. } \\
\text { E. }\end{array}$} & \multirow{2}{*}{ 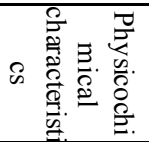 } & \multicolumn{4}{|c|}{$\mathrm{KCL}(\mathrm{mol} / \mathrm{l})$} & \multicolumn{3}{|c|}{$\mathrm{MgCL}_{2}(\mathrm{~mol} / \mathrm{l})$} \\
\hline & & 0 & 0.05 & 0.1 & 0.2 & 0.05 & 0.1 & 0.2 \\
\hline \multirow[b]{6}{*}{ Soil 3} & $\mathrm{~W}_{1}$ & 68.45 & 67.8 & 61,2 & 59.5 & 65.4 & 57.25 & 52.55 \\
\hline & $\mathrm{Wp}$ & 26.41 & 27,66 & 26,06 & 27.8 & 28.3 & 28.70 & 29.53 \\
\hline & $\mathrm{I}_{\mathrm{P}}$ & 42.02 & 40.14 & 35,14 & 31.7 & 37.1 & 28.55 & 23.02 \\
\hline & $\mathrm{W}_{\mathrm{R}}$ & 7.01 & 7,6 & 8,85 & 8.6 & 8.2 & 9.3 & 10.2 \\
\hline & $\mathrm{I}_{\mathrm{R}}$ & 59.55 & 60.2 & 52.35 & 50.9 & 57.2 & 47.95 & 42.35 \\
\hline & VBS & 9.6 & 9 & 6,7 & 7.2 & 8.5 & 7.57 & 5.45 \\
\hline \multirow{6}{*}{ Soil 4} & $\mathrm{~W}_{1}$ & 136 & 135 & 130.44 & 132.25 & 130 & 127.5 & 126 \\
\hline & $\mathrm{W}_{\mathrm{p}}$ & 48.06 & 47.58 & 51.4 & 52.45 & 51.2 & 52.37 & 54.56 \\
\hline & $\mathrm{I}_{\mathrm{P}}$ & 87.94 & 87.42 & 79.04 & 79.8 & 78.8 & 75.13 & 71.44 \\
\hline & $\mathrm{W}_{\mathrm{R}}$ & 11 & 10.47 & 11,8 & 12.4 & 11.2 & 12.5 & 13.5 \\
\hline & $I_{R}$ & 125 & 124,53 & 118.64 & 119.85 & 118.8 & 11.5 & 112.5 \\
\hline & VBS & 43.22 & 43 & 41.5 & 42 & 41.5 & 35.8 & 27.4 \\
\hline
\end{tabular}

The salts may increase the withdrawal limits and this is of course reduces the potential swelling.

\section{Conclusions}

This study has helped to define and measure characteristics mineralogical, chemical, Physical and soil granulometric in the region of Tlemcen.

In this context, it was shown that from simple tests performed in practically all campaigns preliminary reconnaissances, it is possible to qualitatively identify expansive soils and to obtain corre lations fro $m$ approximate estimates of swelling.

The results obtained on the addition of lime milks show that treatment of soils with milk of lime modifies the physicochemical characteristics of soil and the results are quite satisfactory in considerably reducing the phenomenon of swelling, and can be a solution to consider.

The mineral salts change the physicochemical characteristics soils studied, compared with milk of lime, salt concentration has little effect on the swelling and it depends

\section{REFERENCES}

[1] AFNOR., Géotechnique (1998) «Essais de reconnaissance des sols, Tome 1, », Edition AFNOR, 2ième Edition, Paris, France.

[2] ASTM d-4546-90, « standard test methods for(one-dimentinaleswellor settement potentiel of cohésive soils ».

[3] AISSA MAMOUNE S. M., (2009)« Caracteresation et modelisation des argiles de la region de tlemcen en utilisant le reseaux neurons ,» doctoral thesis, Faculty of Technology, University Aboubekr Belkaïd Tlemcen Algérie.

[4] ANAND J and al, (2004)«Studies on Sulfate-Resistant Cement Stabilization Methods to Address Sulfate- Induced Soil Heave,» Journal of Geotechnical and Geoenvironmental Engineering.

[5] Amer Ali .a and Mattheus F.A. G, (2006) « expansive soils, 
Recent advances in characterization and treatment, »Published in the Taylor \& Francis e-Library.

[6] BEKKOUCHE et al(2005) « Techniques de stabilisation des sols expansifs ? »Study days of expansive soils, University Aboubekr Belkaïd Tlemcen Algeria.

[7] BEKKOUCHE et al, (2002) « An experimental investigation on the assessment of the swelling parameters , » International congress in Civil Engineering, Eastern Mediterranean University the Gazimagusa.

[8] AISSA MAMOUNE S.M et al, (2002)« Identification et prévision du gonflement de quelques sols de la région de Tlemcen (Algérie), » Bulletin of the laboratories of Roads and Bridges.

[9] BELABBACI, AISSA MAMOUNE et BEKOUCHE (2011) «Stabilization of soils dispersive soils with milk of lime ,» the 29 meeting of the Academic Association of Civil Engineering,Tlemcen.

[10] CHEN F. H., MA G. S, (1987 ) «Swelling and shrinking behaviours of expansive clays, »International Conference on expansive soils, New Delhi.

[11] DERRICHE Z, Kaoua F, (1997) « Sols gonflants: Méthodologie pour la conception des ouvrages ,»

[12] Technical Review of ENTP, Algeria Equipment.

[13] DJEDID et al, (1997) "Construire sur les sols expansifs, » National Conference of Civil Engineering, Mohamed
BOUDIAF University, Msila.

[14] HACHICHI A. et Fleureau. J.M, (1999) «Caractérisation et stabilisation de quelques sols gonflants d'Algie,» French Review of geotechnical.

[16] HOLTZ R. D et Covacs W.D, (1996) «Introduction à la géotechnique,» Edition of the Polytechnic school of Montreal.

[17] KONAN .k.l, ,2006) « Interactions entre des matériaux argileux et un milieu basique riche en calcium, " Doctoral thesis, university de limoges.

[18] MATEOS, M. and D. T. Davidson, (1963) « Compaction characteristics of soil lime-fly ash mixtures ?» Highway Research board of the national Academy of Sciences.

[19] NOWAMOOZ .H , (2007) «retrait/gonflement des sols argileux compacts et naturels,» Doctoral thesis, , National Polytechnic Institute Lorraine.

[20] NOWAMOOZ .H, (1997) «retrait/gonflement des sols argileux compacts et naturels, ") Doctoral thesis, National Polytechnic Institute Lorraine, 1997.

[21] YOUNG,R,N , OUHADI VR, (2007) « applied clay science expermental study on instability of bases on natural and lime /cement - stabilized clays soils, »Applied clay science vol35.

[22] WILLIAM.J et al, (2003) «Mesured and estimated suction indices for swelling potential classification,» $J$ of Geotechnical and Geoenvironmental Engineering. 